\section{EXCELLENCE IN INTERDISCIPLI- NARY TREATMENT PLANNING}

The British Academy of Cosmetic Dentistry (BACD) is committed to promoting clinical excellence through education and professional development. For accredited members, achieving BACD Fellowship indicates excellence in interdisciplinary treatment planning and the execution of complex treatments to consistently high standards.

The highest and final stage of the BACD's Career Path in Cosmetic Dentistry, Fellowship is aimed at those working at an advanced level who are also sharing their knowledge with the rest of the profession.

The Fellowship is open to accredited members who have either published a scientific article on a clinical subject related to cosmetic dentistry in a peer-reviewed publication, or have given a postgraduate lecture at a BACD meeting or other national/international conference.

Benefits of Fellowship status include use of the title 'Fellow of the British Academy of Cosmetic Dentistry', a plaque acknowledging Fellowship status, which will be superior to the Accreditation plaque, and use of the approved Fellow logo.

Reader response number 62

\section{FEES IN THE EVENT OF A TAX INVESTIGATION}

Tax authorities are specifically targeting sole traders, partnerships and limited companies, which includes private dentists. The effects of an investigation can be incredibly damaging both personally and professionally.

Professional Fee Protection (PFP) Ltd offers an insurance that pays up to $£ 75,000$ towards fees in the event of a tax investigation, ensuring the recovery of costs incurred. Recognised as one of the most successful and innovative providers of fee protection insurance in the UK, PFP has a thorough understanding of the hurdles both individuals and businesses may experience when dealing with the tax authorities.

PFP also offers a 24-hour phone line for legal advice, human resources and employment advice with the HR Plus service.

Reader response number 63

\title{
UNIQUE ONE-STEP FINISHER AND POLISHER
}

The latest addition to Shofu's abrasives and polishers range is One Gloss. This unique one-step finisher and polisher can be used to finish and polish

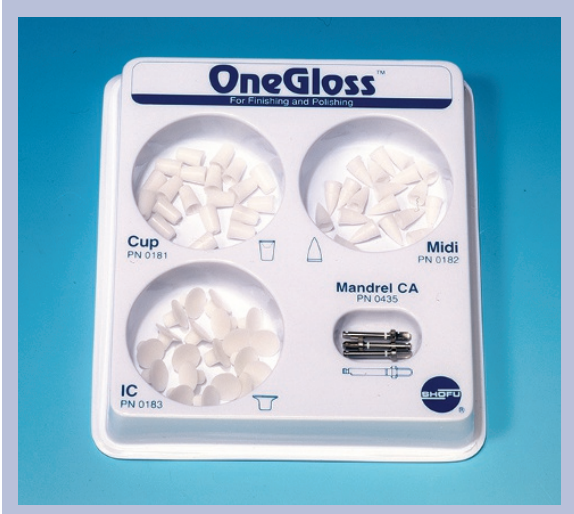

all composite restorations simply by altering the contact pressure on the restoration, without having to change instrument.

One Gloss can also be used for the removal of stains or excess resin cement from tooth surfaces without damaging the enamel, which has proved to be particularly useful in orthodontic cases and polishing after scaling, thus reducing chairside time.

One Gloss is packaged in a set of 60 polishers (20 each of Cup, Midi Point and Inverted Cone shapes) and $3 \times$ CA mandrels plus instructions.

Reader response number 64

\section{HIGH FRACTURE TOUGHNESS}

The unique particle structure and light reflectiveness of GC Gradia Direct provides great aesthetic results. When dealing with more demanding and complex cases, a combination of different shades enables unlimited aesthetic results. GC Gradia Direct offers you the complete assortment from bleach white to dark translucent to outside special shades.

Radiopaque GC Gradia Direct Posterior combines aesthetics with excellent mechanical properties by means of high fracture toughness to resist occlusal stress, high wear resistance and low wear on opposing dentition.

GC have developed a clever new shade guide that takes into account the chroma, hue and value of each composite shade whether you have opted for a single shade or if you are extensively restoring a tooth and require multiple shades. This shade guide incorporates two special shades, which are placed underneath or on top of a standard shade to further enhance your restoration.

Reader response number 65

\section{OPTIMISE YOUR PRACTICE'S POTENTIAL}

Your practice's potential can be optimised with the expert knowledge and advice of the Dental Practice Consultancy Service (DPCS). Created to provide a bespoke service to dentists wanting objective, reliable advice for their business, the DPCS has been a member of the ASPD since 2000.

Shake off the gloom of the current press and embrace new possibilities by receiving a financial health check for your practice. This service includes an in-depth evaluation, projections and ways in which to optimise your practice income. Understanding what it takes for a business to thrive, DPCS can assist practice managers with the purchasing of new premises or the sale of their current one. The expert team can also provide you with the most relevant legal and regulatory advice on issues that affect your business.

Designed with your individual needs in mind, the DPCS is a source of reliable, expert knowledge on a variety of services such as practice valuation, sale and purchase, financial health checks and practice contractual agreements , practice income analysis, energy performance certificates, and all legal and/or regulatory issues. Reader response number 66 